\title{
A CULTURA DA CANA-DE-AÇÚCAR (Saccharum officinarum) E O MANEJO DA IRRIGAÇÃO
}

\author{
Oswaldo Palma Lopes Sobrinho* \\ Gerlange Soares da Silva** \\ Álvaro Itaúna Schalcher Pereira*** \\ Aline Bezerra de Sousa**** \\ Wady Lima Castro Júnior ***** \\ Leonardo Nazário Silva dos Santos*******
}

RESUMO: Tendo em vista a grande competição pelo uso da água, nos próximos anos possivelmente haverá uma mudança no paradigma do manejo da irrigação, visando uma maior eficiência econômica do que a exigência de água pelas plantas. Desta forma, considerando a importância econômica que a cultura de cana-de-açúcar tem no Brasil e no mundo, associada à produção de açúcar, energia e álcool, a presente revisão busca apresentar um estudo sobre as técnicas de otimização no manejo da irrigação para a cana-de-açúcar por ser uma cultura em que o déficit hídrico é um dos fatores que afeta a produtividade. O foco principal proposto foi analisar os resultados científicos sobre a resposta da cana-de-açúcar ao déficit hídrico e a eficiência de uso da água, com as perspectivas socioeconômicas do setor canavieiro. Por meio de análise de dados secundários disponíveis na literatura relacionados ao tema, tanto o rendimento quanto a produção de açúcar e de etanol da cana-deaçúcar irrigada são dependentes da quantidade de água que é aplicada, do manejo da irrigação em combinação com a quantidade correta de adubação, da variedade, da idade do corte, do tipo de solo e do clima. Portanto, o sistema de irrigação para a cultura da cana-de-açúcar mais recomendado é o gotejamento, pois aumenta a produtividade, reduz os tratos culturais e eleva a longevidade dos canaviais.

\footnotetext{
"Mestrando em Ciências Agrárias - Agronomia pelo Instituto Federal de Educação, Ciência e Tecnologia Goiano - Campus Rio Verde - IF Goiano, Brasil. E-mail: oswaldo-palma@hotmail.com

${ }^{* *}$ Doutoranda em Engenharia Agrícola pela Universidade Federal do Recôncavo da Bahia - UFRB, Brasil.

***: Doutor em Engenharia e Ciência de Alimentos pela Universidade Estadual Paulista Júlio de Mesquita Filho UNESP, Docente no Instituto Federal de Educação, Ciência e Tecnologia do Maranhão - Campus Codó - IFMA, Brasil.

${ }^{* * * * *}$ Mestra em Desenvolvimento Regional Sustentável pela Universidade Federal do Cariri - UFCA, Brasil.

****** Doutor em Engenharia Agrícola pela Universidade Federal de Viçosa - UFV, Docente no Instituto Federal de Educação, Ciência e Tecnologia do Maranhão - Campus Codó - IFMA, Brasil.

******* Doutor em Engenharia Agrícola pela Universidade Estadual de Campinas - UNICAMP, Docente no Instituto Federal de Educação, Ciência e Tecnologia Goiano - Campus Rio Verde - IF Goiano, Brasil.
} 
PALAVRAS-CHAVE: Água; Déficit hídrico; Setor canavieiro.

\title{
SUGARCANE CULTIVATION (Saccharum officinarum) AND IRRIGATION MANAGEMENT
}

\begin{abstract}
Due to great competition in water uses, there will be a change in the paradigm of irrigation management for great economic efficiency than water requirements by plants. Due to the economic importance of sugarcane in Brazil and worldwide, associated to the production of sugar, energy and alcohol, current study forwards optimization techniques in irrigation managements for sugarcane. It is a culture highly sensitive to hydric deficit which affects its productivity. The study mainly focuses on scientific results on sugarcane response to hydric deficit and the efficient use of water, with socio-economic perspectives for the sugarcane culture. Secondary data retrieved from the literature show that yield and production of sugar and ethanol from irrigated sugarcane plants depend on the amount of water applied, irrigation management plus the correct quantity of fertilizers, variety and cutting age, soil type and climate. The most recommended irrigation system for sugarcane is the dripper method since it increases productivity, reduces cultural treats and increases sugarcane longevity.
\end{abstract}

KEY WORDS: Water; Hydric deficit; Sugarcane sector.

\section{INTRODUÇÃO}

A cana-de-açúcar é uma cultura que possui alto valor econômico tanto no Brasil quanto no mundo, sendo utilizada na produção de açúcar, energia elétrica e álcool (SILVA et al., 2014). Um dos fatores que mais afeta a produtividade agroindustrial da cana-de-açúcar é o déficit hídrico, sendo este causado pela irregularidade de chuvas nas diversas regiões brasileiras, dentre as quais merece destaque a região Nordeste.

Sua produção mundial é de aproximadamente 1,5 bilhões de toneladas por ano. Na safra 2011/2012, de acordo com a Companhia Nacional de Abastecimento (CONAB), a produção da cana-de-açúcar no Brasil foi de 560,3 milhões de toneladas com produtividade média de $67 \mathrm{t} \mathrm{ha}^{-1}$, em uma área de aproximadamente 8,356 milhões de hectares (COMPANHIA NACIONAL DE ABASTECIMENTO, 2012). A 
safra desta cultura prevista para 2014/2015 segundo o Globo Rural (PRODUÇÃO..., 2014) necessita chegar a 671,69 milhões de toneladas em uma área plantada de 9,13 milhões de hectares, com uma movimentação econômica superior a $R \$ 70$ bilhões, demonstrando a grande importância que esta cultura tem para o Brasil e regiões.

No semiárido, especificamente, no município de Juazeiro (BA), a canade-açúcar tem mostrado um desempenho de destaque em relação às demais áreas de cultivo do país, devido à utilização de tecnologias no manejo da irrigação nos sistemas de produção. Para Silva et al. (2012), o rendimento médio da cana-deaçúcar é em média superior a 91,2 tha-1 , superando a média do rendimento médio estadual $\left(58,7 \mathrm{t} \mathrm{ha}^{-1}\right)$ e nacional $\left(76,6 \mathrm{t} \mathrm{ha}^{-1}\right)$.

Para Souza et al. (2004), a produtividade dessa cultura varia em função de vários fatores, sendo a água um dos que mais contribui para se obter altos rendimentos. Porém, na região Nordeste, a precipitação pluvial é distribuída de forma irregular no decorrer do ano.

Segundo Teodoro et al. (2013) afirmam que pesquisas relacionadas ao consumo de água pela cultura da cana-de-açúcar e o uso de recursos hídricos para o manejo da irrigação se tornam cada vez mais frequentes e necessários de vez que tal operação é um dos fatores de maior influencia na produtividade agrícola, bem como no custo de produção. Assim sendo, deve-se estimar a evapotranspiração da cultura (ET) para o suprimento das necessidades hídricas das plantas. Para que as plantas alcancem o potencial de evapotranspiração (ET) é necessário que o teor de umidade do solo encontre-se igual e/ou próximo da capacidade de armazenamento de água disponível (CAD).

De acordo com Pereira, Angelocci, Sentelhas (2002) e Allen et al. (2005), com a presença de doenças e pragas, baixa fertilidade do solo, salinidade, escassez ou saturação de água, a ET torna-se diferente do valor máximo obtido em condições ótimas, sendo denominada de evapotranspiração real (ET).

A cana-de-açúcar é uma cultura que demanda grandes quantidades de água durante todo o seu ciclo. Partindo dessa premissa, Parkes et al. (2010), Boas et al. (2011), Martins, Reis, Nogueira (2011) afirmam que sistemas de irrigação por gotejamento e microaspersão são mais eficientes no uso da água, sendo 
indispensáveis por reduzir a mão de obra e o consumo de energia, proporcionar maior produção e melhor qualidade do produto e, consequentemente, maior economia e eficiência da aplicação de água.

A presente revisão busca apresentar um estudo sobre as técnicas de otimização no manejo da irrigação para a cana-de-açúcar por ser uma cultura em que o déficit hídrico é um dos fatores que mais afeta a sua produtividade.

\subsection{CARACTERÍSTICAS DA CULTURA DE CANA-DE-AÇÚCAR}

A cultura da cana-de-açúcar (Saccharum officinarum) é uma gramínea perene que teve origem da ilha de Papua, Sudoeste Asiático, nas regiões concentradas entre a Nova Guiné e Indonésia. Esta cultura além de crescer em meio silvestre era também utilizada como planta ornamental para embelezar os jardins e moradias.

Para Miranda (2008), a cultura foi marcada pela expansão juntamente com as migrações náuticas dos habitantes do Oceano Pacífico, disseminando-se nas ilhas do Sul do Pacífico, no Arquipélago da Malásia, em Bengala e na Indochina, sendo certo na Índia o seu surgimento e/ou aparecimento como planta produtora de açúcar. De acordo com Delgado e Cesar (1977) os persas foram os primeiros a desenvolver as técnicas de produção do açúcar sendo estabelecidas as rotas do açúcar entre os países africanos e asiáticos.

Para Horri (2004), a domesticação da cana-de-açúcar na Nova Guiné foi realizada cerca de 8.000 anos antes de Cristo por horticultores neolíticos.

No Brasil as primeiras mudas de cana-de-açúcar foram introduzidas em São Vicente no ano de 1532 por Martim Afonso de Souza, sendo estas provenientes da ilha da Madeira e Açores onde as condições ambientais eram muito similares às do Brasil, e tal fato impulsionou a formação dos primeiros engenhos açucareiros no país (MIRANDA, 2008).

Segundo Mattos (1942), muitos outros se proliferam pela costa brasileira, destacando-se o litoral dos Estados brasileiros de Pernambuco e Bahia - os quais sorveram a maior parte da produção açucareira da colônia. Sendo que a maior contribuição dos engenhos foi estar em um ponto privilegiado, o que facilitava o escoamento da produção, de forma que agilizasse a chegada do produto aos 
mercados consumidores. Alguns engenhos tiveram evolução e transformaram-se em usinas de cana-de-açúcar.

No Brasil, de acordo com a União da Indústria de cana-de-açúcar (UNIÃO DA INDÚSTRIA DE CANA-DE-AÇÚCAR, 2013), o plantio da cana-de-açúcar teve início em São Paulo, no ano de 1522. Atualmente, o Brasil é marcado por ser o maior produtor de cana-de-açúcar, sendo reconhecido mundialmente como um dos líderes na produção desta cultura, seguido dos países da Índia, Tailândia e Austrália. As regiões de cultivo são Sudeste, Centro-Oeste, Sul e Nordeste, permitindo ao país duas safras ao ano e, consequentemente, a produção de açúcar e etanol para os mercados internos e externos (UNIÃO DA INDÚSTRIA DE CANADE-AÇÚCAR, 2017).

A cana-de-açúcar é uma planta semiperene, do gênero Saccharum, família Poaceae, com metabolismo fotossintético $\mathrm{C} 4$ e que possui grande armazenamento de sacarose nos tecidos dos colmos, tornando-a de extrema importância comercial nas lavouras canavieiras, sendo cultivado como um híbrido interespecífico que recebe a denominação Saccharum spp. (RIPOLI; RIPOLI, 2006).

$\mathrm{Na}$ Figura 1 é possível visualizar as estruturas morfológicas da canade-açúcar que favorecem na sua identificação: o desenvolvimento em forma de touceira, caule do tipo colmo, produção de inflorescência, rizoma e raiz fasciculada.

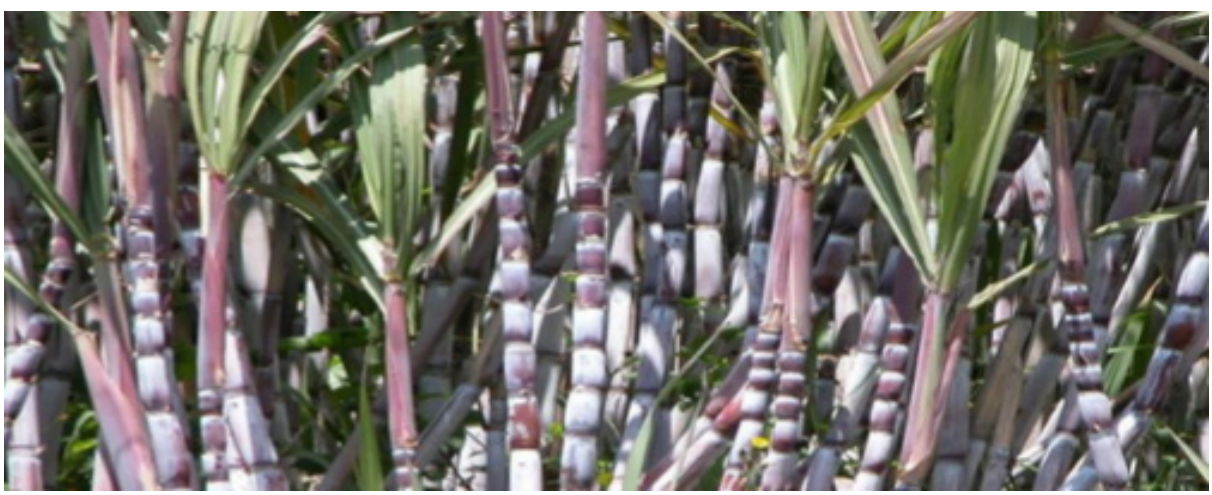

Figura 1. Colmo da cana-de-açúcar e suas estruturas morfológicas Fonte: Companhia Nacional de Abastecimento (2011). 
De acordo com Segato et al. (2006), as folhas da cana-de-açúcar possuem a coloração verde, são sésseis, lancetadas, lineares, largas e agudas. Sendo distribuídas em toda a extensão do colmo, com inserção na região nodal, em fileiras opostas e alternadas (Figura 2).

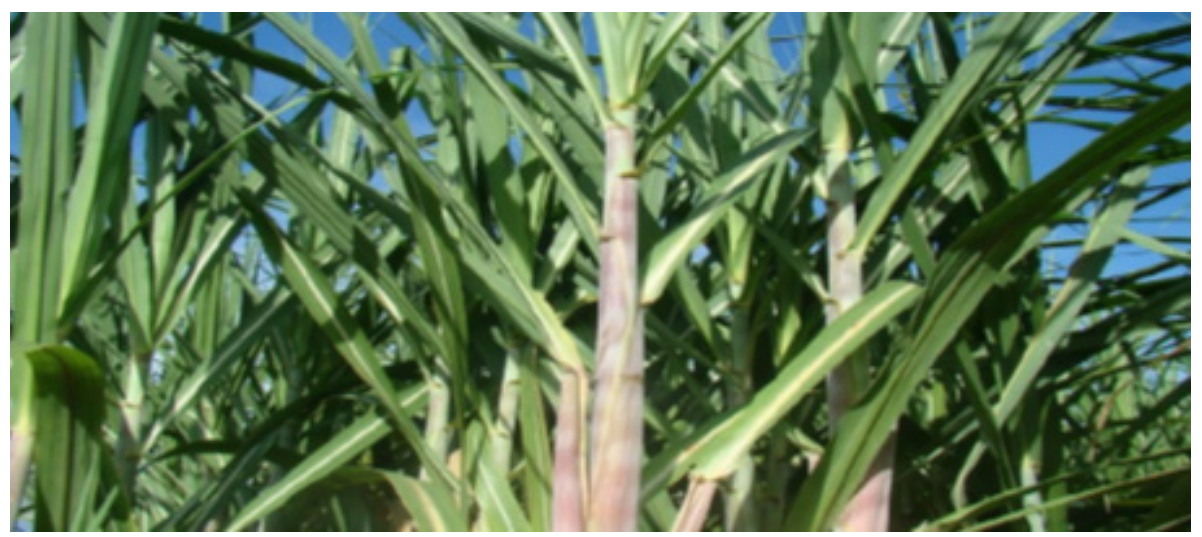

Figura 2. Inserção das folhas no colmo da cana-de-açúcar Fonte: Negrini (2012).

O ciclo fenológico da cana-de-açúcar (primeira e segunda época) é constituído por oito fases distintas; são elas: plantio do tolete; brotação do tolete; início do perfilhamento; perfilhamento intenso; maturação; colmos industrializáveis; corte ou colheita e brotação da soqueira (SEGATO et al., 2006).

O plantio da cana-de-açúcar é feito em duas épocas, dando origem à canaplanta de ano (12 meses) ou à cana-planta de ano e meio (18 meses) (SUGAWARA; RUDORFF, 2011; MIRANDA, 2008), mas após o primeiro corte o ciclo de ambas é anual e ela recebe a denominação de cana soca (BARBOSA, 2010).

Segundo Gascho e Shih (1983) os estádios fenológicos da cana-de-açúcar são separados por brotação e emergência, perfilhamento, crescimento dos colmos e maturação dos colmos. A brotação e emergência se iniciam quando o broto rompe as folhas da gema e se desenvolve rumo à superfície do solo e de forma simultânea a esse processo surgem as raízes do tolete. A emergência do broto ocorre de 20 a 30 dias após o plantio (DAP). O broto é um caule em miniatura que surge acima da superfície do solo e também é denominado de colmo primário. 
Sendo o perfilhamento um processo de emissão de colmos por uma mesma planta, sendo estes designados por perfilhos.

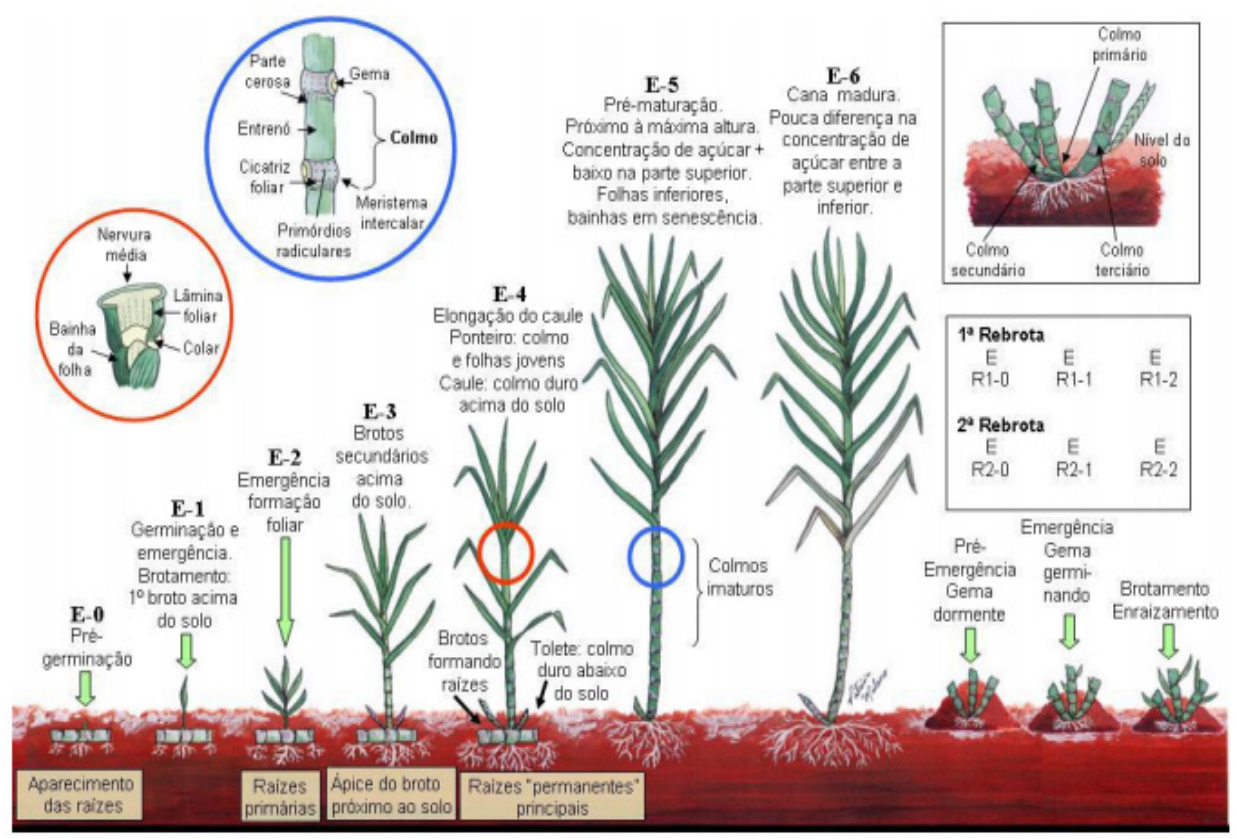

Figura 3. Fases fenológicas da cana-de-açúcar Fonte: Nakano (2011).

Segundo Gava et al. (2011), a demanda hídrica para a cultura da canade-açúcar varia de acordo com as fases fenológicas da cultura. Sendo influenciada também pelas condições ambientais, manejo agrícola, período de plantio e variedade plantada, normalmente a demanda hídrica da cultura é reduzida com a sucessão dos ciclos de cultivo (FARIAS et al., 2008; SILVA et al., 2012).

A cana-de-açúcar é adaptada aos climas tropicais e subtropicais, sendo responsável por demandar grande volume de água em seu sistema de produção, principalmente quando se encontra em pleno desenvolvimento vegetativo, sendo que a produção de biomassa pela cultura é bastante expressiva (TEJERA et al., 2007). 


\subsection{PRODUÇÃO DA CANA-DE-AÇÚCAR}

A safra 2016/2017 para cana-de-açúcar foi estimada em uma produção de 695 milhões de toneladas, sendo utilizada para produzir 39,8 milhões de toneladas de açúcar e 27,9 bilhões de litros de etanol (COMPANHIA NACIONAL DE ABASTECIMENTO, 2017). Ultimamente o etanol já é reconhecido mundialmente por apresentar vantagens ambientais, sociais e econômicas, atraindo um crescente interesse na tecnologia brasileira, o que vem refletindo em um substancial aumento da produção de cana-de-açúcar no país nos últimos anos. $\mathrm{O}$ aumento na produção requer investimentos em infraestrutura e novas usinas e também na expansão da área plantada.

\subsection{DÉFICIT HÍDRICO}

Para Cattivelli et al. (2008), a frequência e a intensidade do déficit hídrico são os fatores mais importantes à limitação da produção agrícola mundial. Neste contexto esforços têm sido realizados com o objetivo de melhorar a produtividade dos cultivos agrícolas sob condições de seca.

Moreno-Fonceca (2009) define o déficit hídrico como todo conteúdo de água de um tecido ou célula que está abaixo do conteúdo de água mais alto exibido no estado de maior hidratação e ele ocorre quando a perda de água excede a absorção. Sendo que na maioria das plantas estão sujeitas a uma deficiência de água durante o dia seguido de uma recuperação à noite. Assim sendo, o fenômeno chamado estresse é responsável por ocasionar nas plantas alterações fisiológicas e bioquímicas, ocasionando mudanças estruturais e funcionais em todos os níveis organizacionais, e estas ocorrem das moléculas grandes tais como proteínas e lipídios, e a agregações delas nas membranas, para as mais complexas organelas (cloroplastos, mitocôndrias), e, em seguida, nas células, tecidos e órgãos, através de toda a planta.

Os pesquisadores dividiram os mecanismos de respostas da planta à deficiência hídrica em quatro tipos, tais como: a limitação do crescimento para minimizar a perda de água; as adaptações morfológicas e fisiológicas, além de 
alterações metabólicas. As três primeiras formas de reação da planta ao estresse hídrico são processos complexos, conhecidos de forma incompleta, porém muitos progressos já foram obtidos no entendimento das mudanças ocorridas no metabolismo da planta, quando submetida ao estresse hídrico (BARBOSA, 2010).

\subsection{DEFICIÊNCIA HÍDRICA NA CANA-DE-AÇÚCAR}

Bernardo, Soares e Mantovani (2005) relatam que o consumo diário de água para a cana-de-açúcar varia entre 2 a $6 \mathrm{~mm} / \mathrm{dia}$, nas principais regiões produtoras, podendo divergir entre as variedades utilizadas e o estágio de desenvolvimento da cultura. A relação entre o consumo de água e a produção da cana pode chegar a 12,1 $\mathrm{mm} / \mathrm{t}$ (PERES, 1988).

A cultura da cana-de-açúcar é sensível ao estresse hídrico (MAAS; HOFFMAN, 1977). Os autores Doorembos e Kassam (1979) afirmam que as consequências da deficiência hídrica variam de acordo com o estádio de desenvolvimento da cultura (GASCHO; SHIH, 1983). Dessa forma, os dois primeiros estádios de crescimento são caracterizados por serem os mais suscetíveis ao déficit hídrico; já o terceiro estádio responde a uma lâmina aplicada, mas o déficit hídrico não ocasiona muitos prejuízos à produtividade; e o quarto estádio responde positivamente ao déficit hídrico (BERNARDO; SOARES; MANTOVANI, 2005).

Para a fase fenológica, o déficit hídrico tem maior ou menor impacto na produtividade agrícola (PIMENTEL, 2004; MACHADO et al., 2009). A cana-de-açúcar apresenta expressiva demanda hídrica no período do perfilhamento e do rápido crescimento que ocorre 60 a 150 dias após plantio (RAMESH, 2000; MACHADO et al., 2009) sendo relatado que é nesse estádio fenológico que a cultura está mais suscetível ao déficit hídrico, porque a planta obtém um rápido desenvolvimento, expressiva área foliar e dessa forma ela necessita de uma maior quantidade de água para viabilizar a troca de gases com a atmosfera (PIRES, ARRUDA; SAKAY, 2008). 


\subsection{IMPORTÂNCIA DA IRRIGAÇÃO PARA A CULTURA DE CANA-DE-AÇÚCAR}

Para Mantovani, Bernardo e Palaretti (2006), a importância da irrigação pode ser resumida em algumas vantagens: seguro contra secas; maior eficiência no uso de fertilizantes; melhor produtividade das culturas; redução do consumo de energia; melhor qualidade do produto; possibilidade de fazer um programa de cultivo com colheitas fora da época tradicional; e introdução de culturas caras minimizadas o custo do investimento. Sendo consideradas também as vantagens socioeconômicas, dentre elas a geração de empregos, aumento de renda, redução do êxodo rural e desenvolvimento da região.

A Irriger (2013), com adoção de técnicas de manejos adequados em áreas de cultivo de cana-de-açúcar, afirma ser viável e traz benefícios significativos à produtividade e crescimento da cultura.

\subsection{MANEJO DA IRRIGAÇÃO NA CANA-DE-AÇÚCAR}

Arantes (2012) afirma que o cultivo da cana-de-açúcar irrigada ocasiona um aumento da produtividade e do número de cortes por plantio, além de promover uma maior eficiência econômica da atividade sucroalcooleira. Destarte, a irrigação e o seu manejo racional são fatores de grande importância na maximização da produtividade do setor canavieiro (DANTAS NETO et al., 2006; GAVA et al., 2011).

A exigência hídrica da cana-de-açúcar é de 1500 a $2500 \mathrm{~mm}$, durante o seu ciclo (DOORENBOS; KASSAM, 1979). Dessa forma, o manejo da irrigação para esta cultura necessita ser realizado levando-se em consideração as características físicas do solo, sendo recomendadas determinadas lâminas para cada estádio do ciclo fenológico.

A cana-de-açúcar submetida ao estresse hídrico no terceiro e quarto período do seu ciclo, 257 a 272 e 302 a 347 dias após o plantio, apresenta redução de $8,3 \%$ a $15 \%$ no rendimento produtivo (WIEDENFELD, 2000).

Para Duarte (2007), no manejo da cana-de-açúcar irrigada é de grande importância caracterizar as fases de desenvolvimento da cultura, a fim de possibilitar a aplicação adequada de água ao longo do ciclo. Assim, é possível 
dividir-se em quatro os estágios de desenvolvimento da cana de doze meses, dentre elas, a germinação e emergência, com duração de 1 mês, o perfilhamento e estabelecimento da cultura, com duração entre 2 a 3 meses, desenvolvimento da cultura, com duração 6 a 7 meses, e, por último, a maturação fisiológica, com duração de 2 meses.

Para Oliveira, Ramos e Aquino (2013), pode-se destacar como estratégias de manejo de irrigação aplicadas à cana-de-açúcar: irrigação de salvação, irrigação com déficit hídrico controlado, irrigação suplementar e irrigação plena. Afirmam ainda que a irrigação de salvação consiste em duas a três aplicações de água ou vinhaça na cana-de-açúcar, planta ou soca, com finalidade de garantir a germinação e o desenvolvimento inicial das plântulas. Sendo que nesta modalidade de aplicação não há o rigor de se atender plenamente a necessidade real de água da cultura. É recomendável uma única aplicação com cerca de 40 a $80 \mathrm{~mm}$, em um mês, de água ou vinhaça para solos argilosos; para solos arenosos, pode-se aumentar o número de irrigações com diminuição da lâmina de água aplicada por vez.

$\mathrm{Na}$ irrigação com déficit hídrico controlado, de acordo com Oliveira, Ramos e Aquino (2013), atende-se parte da necessidade hídrica das plantas, podendo ser aplicado este tipo de manejo em todo o ciclo da cultura e/ou nas fases de desenvolvimento e maturação fisiológica. A aplicação de água na irrigação suplementar é feita quando a necessidade hídrica da cultura é maior que a quantidade de água disponível no solo, por falta ou irregularidade das chuvas. $\mathrm{Na}$ irrigação plena são feitas aplicações de água de forma a suprir totalmente a necessidade da cultura, sendo este tipo de manejo pouco usual por ser mais oneroso.

Visando um bom manejo de irrigação da cultura é preciso observar os valores de evapotranspiração, transpiração da planta junto com evaporação do solo, que são determinados e ajustados ao clima e solo local. É preciso verificar também o ciclo da planta, a variedade, o espaçamento, e o sistema de irrigação.

Para Silva et al. (2015), trabalhando com cana-de-açúcar em Goiânia (GO), observaram que a cana-soca mostrou ter maior dependência de irrigação em relação à cana-planta. Para Carmo (2013), a evaporação deve ser reduzida na medida do possível, porém, a transpiração é necessária para o crescimento e desenvolvimento da planta. 
Os métodos empregados para a cultura da cana-de-açúcar são por superfície, aspersão e localizada.

$\mathrm{Na}$ irrigação por superfície a água é aplicada em sulcos de irrigação paralelos à linha da planta, de forma mais concentrada, como pode ser observado na Figura 4. A Irriger (2013) relata que este tipo de irrigação é aconselhado para solos de textura médio-argilosa e terrenos planos, devido ao método ser de baixa eficiência de aplicação da água. Para tanto, é necessária a sistematização do terreno para que este apresente condições adequadas de condição e distribuição de água. Conforme Mantovani, Bernardo e Palaretti (2006) é o método que consome maior quantidade de água, com baixa eficiência de aplicação e não permite a fertirrigação.

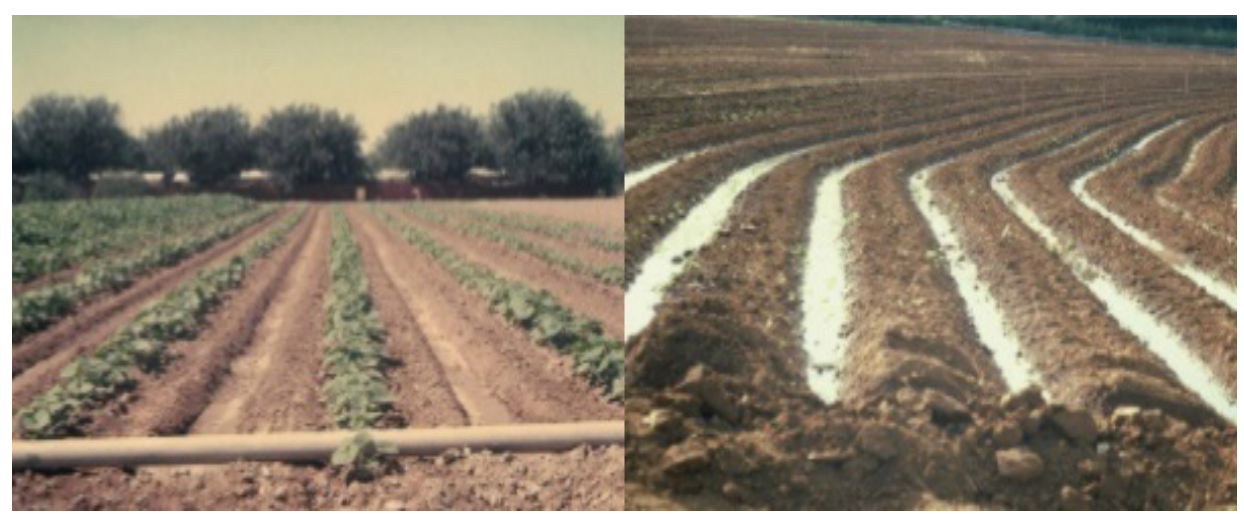

Figura 4. Sistema de irrigação por superfície em cana-de-açúcar Fonte: Mantovani, Bernardo e Palaretti (2009).

$\mathrm{Na}$ irrigação por aspersão na cana-de-açúcar a água é aspergida sob pressão em forma de gotas que simulam a chuva. Os aspersores são conectados a tubulações de diferentes diâmetros, e estas a uma bomba centrífuga, responsável pela pressurização do sistema, podendo ser visualizados pela Figura 5. É um método muito utilizado devido à sua boa aplicabilidade. Além disso, apresenta boa uniformidade de aplicação de água, cerca de 75 a 90\% (BERNARDO; SOARES; MANTOVANI, 2008). 


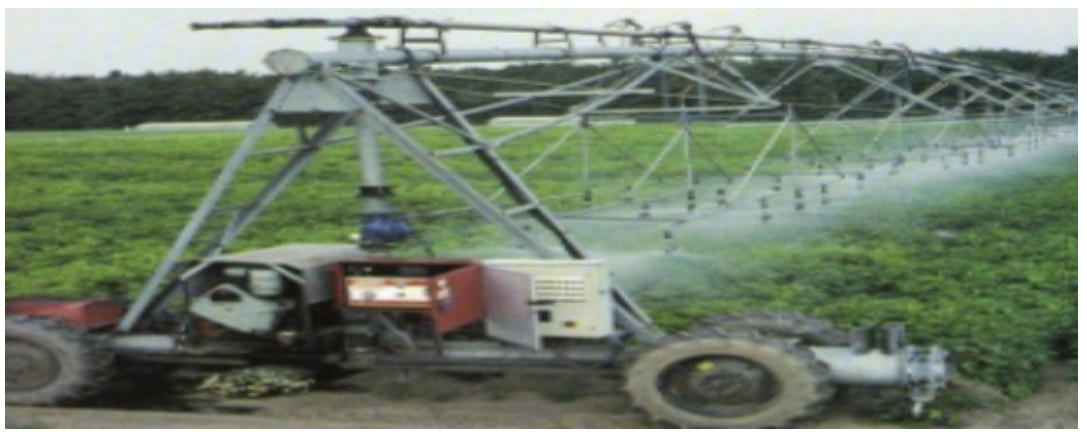

Figura 5. Sistema mecanizado de aspersão

Fonte: Mantovani, Bernardo e Palaretti (2009)

A irrigação localizada é o método mais recente da irrigação, onde a água é aplicada em apenas uma fração do sistema radicular das plantas, ou seja, diretamente na raiz (Figura 6). Não possui restrição em termos de textura do solo e topografia do terreno. Esse sistema permite a aplicação de fertilizantes via água de irrigação, reduzindo bastante os custos com mão de obra com essa prática. Como desvantagem, apresenta elevado investimento inicial com a aquisição das linhas gotejadoras, tubulações, filtros e acessórios (IRRIGER, 2013). Porém, esta técnica pode apresentar um grande problema que é o entupimento dos emissores, exigindo assim operações de manutenção preventivas adequadas e constantes.

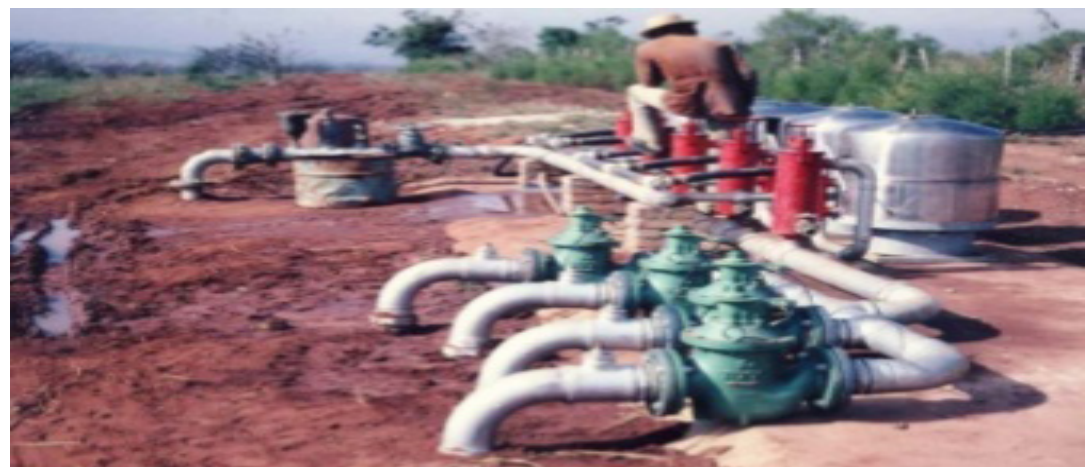

Figura 6. Irrigação localizada Fonte: Frizzone (2014). 
Silva (2009), trabalhando com cana-de-açúcar cultivada em Teotônio Vilela (AL), calculou-se a EUA e encontraram-se os seguintes resultados: a lâmina de 100 mm obteve o melhor resultado, com $8,2 \mathrm{~mm} \mathrm{t}^{-1}$, enquanto a lâmina de $650 \mathrm{~mm}$ foi a menos eficiente, com $14,8 \mathrm{~mm} \mathrm{t}^{-1}$. A EUA média das lâminas de $50 \mathrm{a} 650 \mathrm{~mm}$ foi de $11,7 \mathrm{~mm} \mathrm{t}^{-1}$. Os resultados mostram que as lâminas mais baixas apresentaram melhores EUA.

Teodoro (2011), trabalhando com cana-de-açúcar, indica que a resposta para esta cultura é maior quando a quantidade de água aplicada fica em torno de $25 \%$ da ETo.

Moura et al. (2005) estudaram em Tabuleiros costeiros da Paraíba a resposta da cultura em regime irrigado e não irrigado e observaram efeitos positivos da irrigação sobre o rendimento de açúcar, álcool e colmos. Os autores utilizaram sistema de irrigação por pivô central com turno de rega de 12 dias e observaram que a produtividade média dos colmos para o regime com e sem irrigação foi de $92 \mathrm{t} \mathrm{ha}^{-1}$ e $77 \mathrm{t} \mathrm{ha}^{-1}$, respectivamente. O cultivo de sequeiro reduziu em $20 \%$ a produtividade de colmos. A média geral de colmos obtida nesta pesquisa foi de 84 tha ${ }^{-1}$.

Campos et al. (2012), trabalhando com lâminas crescentes (sem irrigação; 20; 40; 60; e $80 \mathrm{~mm}$ ) de irrigação de salvamento, obtiveram valores inferiores quando aplicados os tratamentos de $60 \mathrm{~mm}$ em seu trabalho conduzido no município de Pirenópolis (GO), obtendo valores na ordem de 10,50 perfilhos/metro (com palha) e 11,30 perfilhos/metro (sem palha). No tratamento sem irrigação, conduzido pelos mesmos autores, obtiveram valores na ordem de 11,30 perfilhos/metro (no sistema conduzido com palha) e 10,40 perfilhos/metro (sem palha), sendo inferiores aos valores médios obtidos no experimento que ficaram na ordem de 13,70 perfilhos/ metro.

Farias (2006), estudando em áreas agrícolas nos tabuleiros costeiros da Paraíba o efeito da lâmina de irrigação e doses de zinco na variedade de cana-deaçúcar SP-79 1011, percebeu que a irrigação plena e o sistema de irrigação utilizado por aspersão via pivô central, com turno de irrigação de 9 dias, tiveram resultados de produtividade agrícola significativos para lâminas e níveis de zinco $(\mathrm{p}<0,01)$. Foi possível observar que a cana irrigada com 25\% (256 mm) da ET atingiu um 
nível de produtividade $\left(52,5 \mathrm{tha}^{-1}\right)$ superior às demais áreas irrigadas da destilaria, as quais foram irrigadas com $40 \%$ da ETc em turno de rega de 12 a 14 dias. A maior produtividade alcançada foi $88,10 \mathrm{t} \mathrm{ha}^{-1} \mathrm{com} 100 \%$ da ETc $(1026,57 \mathrm{~mm})$.

\section{CONSIDERAÇÕES FINAIS}

O manejo da irrigação acredita no uso de forma criteriosa do recurso hídrico disponível para se atingir e/ou alcançar altas produtividades das culturas com o uso eficiente da água, da energia e de outros fatores de produção. Levandose em consideração outros objetivos, como a maximização da produção vegetal por unidade de custo da mão de obra ou do capital investido, podem ser também estabelecidos.

O manejo da irrigação da cana-de-açúcar é de suma importância para o crescimento, desenvolvimento e aumento de produtividade da cultura. Assim sendo, os impactos das deficiências hídricas na produção da cana-de-açúcar causadas pela irregularidade das chuvas são fatores de maior peso no balanço dos rendimentos agronômicos. Dessa forma, se fazem necessárias técnicas de otimização que visem o correto manejo da irrigação para a cana-de-açúcar por ser uma cultura em que o déficit hídrico é um dos fatores que mais afeta a sua produtividade.

Portanto, o sistema de irrigação para a cultura da cana-de-açúcar mais recomendado é o gotejamento, pois aumenta a produtividade, reduz os tratos culturais e eleva a longevidade dos canaviais.

\section{REFERÊNCIAS}

ALLEN, R. G.; PEREIRA, L. S.; SMITH, M.; RAES, D.; WRIGHT, J. L. FAO-56 dual crop coefficient method for estimating evaporation from soil and application extensions. Journal of Irrigation and Drainage Engineering, v. 131, p. 1-13, 2005. DOI: 10.1061/(ASCE)0733-9437(2005)131:1(2).

ARANTES, M. T. Potencial produtivo de cultivares de cana-de-açúcar sob os manejos irrigado e sequeiro. 2012. 36 f. Dissertação (Mestrado em Agronomia) - Faculdade de Ciências Agronômicas, Universidade Estadual Paulista, Botucatu, 2012. 
BARBOSA, F. S. Resistência à seca em cana-de-açúcar para diferentes níveis de disponibilidade hídrica no solo. 2010. 81 f. Dissertação (Mestrado em Agronomia) - Escola Superior de Agricultura Luiz Queiroz, Piracicaba, 2010.

BERNARDO, S.; SOARES, A. A.; MANTOVANI, E. C. Manual de irrigação. 7. ed. Viçosa: UFV, 2005. $611 \mathrm{p}$.

BERNARDO, S.; SOARES, A. A.; MANTOVANI, E. C. Manual de irrigação. 8. ed. Viçosa: UFV, 2008. 625 p.

BOAS, R. C. V.; PEREIRA, G. M.; REIS, R. P.; LIMA JÚNIOR, J. A.; CONSONI, R. Viabilidade econômica do uso do sistema de irrigação por gotejamento na cultura da cebola. Ciência e Agrotecnologia, v. 35, p. 781-788, 2011. http://dx.doi.org/10.1590/ S1413- 70542011000400018. Acesso em: 12 mar. 2018.

CATTIVELLI, L. et al. Drought tolerance improvement in crop plants: an integrated view from breeding to genomics. Field Crops Research, v. 105, p. 1-14, 2008.

CARMO, J. F. A. Evapotranspiração da cana-de-açúcar irrigada por gotejamento subsuperficial no submédio do vale do São Francisco. Dissertação (Mestrado em Engenharia Agrícola) - Universidade Federal do Vale do São Francisco, Campus de Juazeiro, BA, 2013.

CAMPOS, P. F.; ALVES JÚNIOR, J.; SOARES, R. A. B.; RIBEIRO, H. P.; EVANGELISTA, A. W. P. Resposta da cultura da cana-de-açúcar a irrigação de salvamento e ao uso da palha na cobertura do solo na região do cerrado. In: CONGRESSO LATINOAMERICANO Y DEL CARIBE DE INGENIERÍA AGRÍCOLA, 10., CONGRESSO BRASILEIRO DE ENGENHARIA AGRÍCOLA, 41., 2012, Londrina. Anais eletrônicos [...]. Londrina: Associação Brasileira de Engenharia Agrícola, Associação Latino-Americana e do Caribe de Engenharia Agrícola, 2012.

COMPANHIA NACIONAL DE ABASTECIMENTO. Acompanhamento de safra brasileira: cana-de-açúcar. Terceiro levantamento. Brasília: Conab, dezembro, 2012. $18 \mathrm{p}$.

COMPANHIA NACIONAL DE ABASTECIMENTO. Levantamento/2017. 2017. Disponível em: http://www.conab.gov.br. Acesso em: set. 2017. 
COMPANHIA NACIONAL DE ABASTECIMENTO. Primeiro levantamento/2011. 2011. Disponível em: http://www.conab.gov.br. Acesso em: 3 maio 2018.

DANTAS NETO, J.; FIGUEIRÊDO, J. L. C.; FARIAS, C. H. A. de; AZEVEDO, H. M. de; AZEVEDO, C. A. V. de. Resposta da cana-de-açúcar, primeira soca, a níveis de irrigação e adubação de cobertura. Revista Brasileira de Engenharia Agrícola e Ambiental, v. 10, p. 283-288, 2006.

DELGADO, A. A.; AZEVEDO CÉSAR, M. A. Elementos de tecnologia e engenharia do açúcar de cana. Piracicaba: Escola Superior de Agricultura Luiz de Queiroz, 1977. v. 2.

DOORENBOS, J.; KASSAM, A. H. Yield response to water irrigation and drainage paper 33. Rome: Food and Agriculture Organization of the United Nations, 1979. $193 \mathrm{p}$.

DUARTE, A. M. A. Avaliação do desempenho agronômico de seis variedades de cana-de-açúcar, no primeiro corte, em condições de cultivo irrigado, em Jaíba - MG. 2007. Trabalho de Conclusão de Curso (Graduação em Agronomia) Universidade Estadual de Montes Claros, Janaúba, MG, 2007.

FARIAS, C. H. A. Otimização do uso da água e do zinco na cana-de-açúcar em tabuleiro costeiro paraibano. 2006. $142 \mathrm{f}$. Tese (Doutorado em Recursos Naturais) - Universidade Federal de Campina Grande, Campina Grande, PB, 2006.

GASCHO, G. J.; SHIH, S. F. Sugar cane. In: TEARE, I. D.; PEET, M. M. (ed.). Crop-water relations. New York: Wiley-Interscience, 1983. p. 445-479. Disponível em: http://www.agencia.cnptia.embrapa.br/gestor/cana-deacucar/arvore/CONTAG01_68_22122006154840.html. Acesso em: set. 2018.

GAVA, G. J. de C.; SILVA, M. A.; SILVA, R. C.; JERONIMO, E. M.; CRUZ, J. C. S.; KOLLN, O. T. Produtividade de três cultivares de cana-de-açúcar sob manejos de sequeiro e irrigado por gotejamento. Revista Brasileira de Engenharia Agrícola e Ambiental, Campina Grande, v. 15, n. 3, p. 250-255, 2011.

PRODUÇÃO de cana deve aumentar 2\% na safra 2014/2015. Globo Rural, abr. 2014. Disponível em: http://revistagloborural.globo.com/Noticias/Agricultura/Cana/ 
noticia/2014/04/producao-decana-deve-aumentar-2-na-safra-20142015.html. Acesso em: 5 jun. 2018.

HORRI, J. A cana-de-açúcar como matéria-prima. Piracicaba: Departamento de Alimentos, Nutrição e Agroindústria, Escola Superior de Agricultura Luiz de Queiroz, 2004. 27 p.

IRRIGER. Irrigação. 2013. Disponível em: http://irriger.com.br/. Acesso em: 18 jul. 2018.

MAAS, E. V.; HOFFMAN, G. J. Crop salt tolerance - current assessment. Journal of Irrigation and Drainage Division, v. 103, p. 115-134, 1977.

MACHADO, R. S.; RIBEIRO, V.; MARCHIORI, P. E. R.; MACHADO, D. F. S. P.; LANDELL, M. G. A. Respostas biométricas e fisiológicas ao déficit hídrico em cana-de-açúcar em diferentes fases fenológicas. Pesquisa Agropecuária Brasileira, Brasília, v. 44, n. 12, p. 1575-1582, 2009.

MANTOVANI, E. C.; BERNARDO, S.; PALARETTI, L. F. Irrigação: princípios e métodos. 2. ed. atual. e aum. Viçosa: UFV, 2009. 355 p.

MANTOVANI, E. C.; SALASSIER, B.; PALARETTI, L. F. Irrigação: princípios e métodos. Viçosa: UFV, 2006. 318 p.

MARTINS, C. A. S.; REIS, E. F.; NOGUEIRA, N. O. Análise do desempenho da irrigação por microspray na cultura do café conilon. Enciclopédia Biosfera, v. 7, p. 1-13, 2011.

MATTOS, A. R. Açúcar e álcool no Brasil. São Paulo: Companhia Editora Nacional, 1942.

MIRANDA, J. R. História da cana-de-açúcar. Campinas: Komedi, 2008. 167 p.

MORENO-FONCECA, L. P. Respuesta de las plantas alestrés por deficit hídrico: una revisión. Agronomía Colombiana, v. 27, p. 179-191, 2009.

MOURA, M. V. P. da S.; FARIAS, C. H. A.; AZEVEDO, C. A. V. de; PONTES NETO, J.; 
AZEVEDO, H. M. de; PORDEUS, R. V. Doses de adubação nitrogenada e potássica em cobertura na cultura da cana-de-açúcar, primeira soca, com e sem irrigação. Ciência Agrotécnica, v. 29, n. 4, p. 753-760, 2005.

NEGRINI, E. J. Cana: botânica e morfologia. 2012. Disponível em: https:/html2-f. scribdassets.com/26819e8urk1llzho/images/1-9a92b163e3.jpg. Acesso em: set. 2017.

OLIVEIRA, R. A.; RAMOS, M. M.; AQUINO, L. A. Irrigação. In: SANTOS, F.; BORÉM, A. Cana-de-açúcar: do plantio à colheita. Viçosa: UFV, 2013. p. 153-180.

PARKES, M.; YAO, W. W.; MA, X. Y.; LI, J. Simulation of point source wetting pattern of subsurface drip irrigation. Irrigation Science, v. 29, p. 331-339, 2010.

PEREIRA, A. R.; ANGELOCCI, L. R.; SENTELHAS, P. C. Agrometeorologia: fundamentos e aplicações práticas. Guaíba: Agropecuária, 2002. 478 p.

PERES, J. G.; Determinação dos coeficientes de cultura $\left(\mathbf{K}_{\mathbf{c}}\right)$ : ciclo de cana soca. Piracicaba: Escola Superior de Agricultura Luiz de Queiroz, 1988.

PIRES, R. C. M.; ARRUDA, F. B.; SAKAY, E. Irrigação e drenagem. In: DINARDOMIRANDA, L. L.; VASCONCELOS, A. C. M. de; LANDELL, M. G. de A. (ed.). Cana-deaçúcar. Campinas: Instituto Agronômico, 2008. p. 631-970.

RAMESH, P. Effect of different levels of drought during the formative phase on growth parameters and its relationship with dry matter accumulation in sugarcane. Journal Agronomy \& Crop Science, v. 185, p. 83-89, 2000.

RIPOLI, M. L. C.; RIPOLI, T. C. C. Plantadoras nos canaviais. Cultivar Máquinas, v. 6, n. 55, p. 16-19, 2006.

SEGATO, S. V.; PINTO, A. S.; JENDIROBA, E.; NOBREGA, J. C. M. Atualização em produção de cana-de-açúcar. Piracicaba: ESALQ/USP, 2006. 415 p.

SILVA, M. A.; ARANTES, M. T.; RHEIN, A. F. L.; GAVA, G. J. C.; KOLLN, O. T. Potencial produtivo da cana-de-açúcar sob irrigação por gotejamento em função de variedades e ciclos. Revista Brasileira de Engenharia Agrícola e Ambiental, v. 
18, p. 241-249, 2014. DOI: http://dx.doi.org/10.1590/S1415-43662014000300001.

SILVA, S.; TEODORO, I.; LYRA, G. B.; SOUZA, J. L.; DANTAS NETO, J. Adaptação do método de $\mathrm{K}_{c}$ "dual" (FAO-56) para a cana-de-açúcar irrigada por gotejamento. ABEAS, v. 27, p. 87-93, 2012. DOI: http://dx.doi.org/10.12722/0101-756X. v27n02a02.

SILVA, A. B. P. Avaliações do projeto de gotejamento em cana-de-açúcar da Usina Seresta. In: SIMPÓSIO DA AGROINDÚSTRIA DA CANA-DE-AÇÚCAR NO ESTADO DE ALAGOAS, 26., 2009, Maceió. Anais [...]. Maceió: Sociedade dos Técnicos Açucareiros e Alcooleiros do Brasil, 2009. (CD-ROM).

SILVA, N. F. S.; CUNHA, F. N.; TEIXEIRA, M. B.; SOARES, F. A. L.; MOURA, L. C. Crescimento vegetativo da cana-de-açúcar submetida a lâminas de irrigação e fertirrigação nitrogenada via gotejamento subsuperficial. Revista Brasileira de Agricultura Irrigada. v. 9, n. 2, p. 79-90, 2015.

SOUZA, J. L. et al. Análise da precipitação pluvial e temperatura do ar na região do Tabuleiro Costeiro de Maceió, AL, período 1972-2001. Revista Brasileira de Agrometeorologia, v. 12, p. 131-141, 2004.

SUGAWARA, L. M.; RUDORFF, B. F. T. Acompanhamento do crescimento vegetativo da cana-de-açúcar por meio de séries temporais de NDVI do sensor Modis. In: SIMPÓSIO BRASILEIRO DE SENSORIAMENTO REMOTO, 15., 2011, Curitiba. Anais [...]. p. 391. Curitiba: INPE, 2011.

TEJERA, N. A.; RODÉS, R.; ORTEGA, E.; CAMPOS, R.; LLUCH, C. Comparative analysis of physiological characteristics and yield components in sugarcane cultivars, Field Crops Research, v. 102, p. 64-72, 2007.

TEODORO, I. et al. Isoquantas de produtividade da cana-de-açúcar em função de níveis de irrigação e adubação nitrogenada. Irriga, v. 18, p. 387-401, 2013. DOI: http:// dx.doi.org/10.15809/irriga.2013v18n3p387.

TEODORO, I. Respostas técnico-econômicas da cana-de-açúcar a níveis de irrigação e adubação nitrogenada. 2011. 100 f. Tese (Doutorado em Engenharia Agrícola) - Universidade Federal de Campina Grande, Campina Grande, 2011. 
UNIÃO DA INDÚSTRIA DE CANA-DE-AÇÚCAR. 2013. Setor sucroenergético: histórico do setor. Disponível em: http://www.unica.com.br. Acesso em: 23 mar. 2018.

WIEDENFELD, R. P. Water stress during different sugar cane growth periods on yield and response to $\mathrm{N}$ fertilizer. Agriculture Water Management, v. 43 p. 173$182,2000$.

Recebido em: 27/07/2017

Aceito em: 24/08/2018 